\title{
Elucidating the Promotional Effect of Cerium in the Dry Reforming of Methane
}

\author{
Alberto Rodriguez-Gomez, ${ }^{[a][b] *}$ Angeles Lopez-Martin, ${ }^{[a]}$ Adrian Ramirez, ${ }^{[b]}$ Jorge Gascon ${ }^{[b]}$ and Alfonso \\ Caballero ${ }^{[a] *}$
}

[a] A. Rodriguez-Gomez, A. Lopez-Martin, Prof. A. Caballero

Instituto de Ciencia de Materiales de Sevilla (CSIC-University of Seville) and Departamento de Quimica Inorganica

University of Seville

Av. Americo Vespucio, 49; 41092 Seville (Spain)

E-mail: alberto.rodriguezgomez@kaust.edu.sa; caballero@us.es.

[b] A. Rodriguez-Gomez, A. Ramirez, Prof. J. Gascon

KAUST Catalysis Center (KCC), Advanced Catalytic Materials

King Abdullah University of Science and Technology

Thuwal 23955, Saudi Arabia

Supporting information for this article is given via a link at the end of the document.

\begin{abstract}
A series of $\mathrm{Ni}-\mathrm{Ce}$ catalysts supported on SBA-15 has been prepared by co-impregnation, extensively characterized and evaluated in the carbon dioxide reforming of methane (DRM). The characterization by TEM, XRD and TPR has allowed us to determine the effect of metal loading on metal dispersion. Cerium was found to improve nickel location inside the mesopores of SBA-15 and to suppress coke formation during the DRM reaction. The analysis by XPS allowed us to associate the high cerium dispersion with the presence of low-coordinated $\mathrm{Ce}^{3+}$ sites, being main responsible for its promotional effect. A combination of XAS and XPS has permitted us to determine the physicochemical properties of metals under reduction conditions. The low nickel coordination number determined by XAS in Ni-Ce doped systems after reduction suggests the generation of very small nickel particles which showed greater catalytic activity and stability in the reaction, and a remarkable resistance to coke formation.
\end{abstract}

\section{Introduction}

Cerium oxide has received considerable interest as a promoter for several catalytic applications including the selective oxidation of CO (PROX), water-gas-shift reaction (WGS), fluid catalytic cracking of petroleum (FCC), and as a component of the automotive three-way catalytic converters ${ }^{[1-3]}$ Most of the benefits of cerium promotion in heterogeneous catalysis are attributed to the $\mathrm{Ce}^{3+} / \mathrm{Ce}^{4+}$ interconversion capacity which allows an enhanced oxygen mobility. ${ }^{[2-6]}$ Moreover, the physical and chemical properties of the active metal phase could be modified in the presence of ceria, affecting the performance in hydrogen production reactions. ${ }^{[7-11]}$ Hence, cerium oxide has been widely explored in the reforming of hydrocarbons, as a promoter of highly active noble metals $(\mathrm{Pt}, \mathrm{Rh})^{[7,12-15]}$ or cheaper non-noble alternatives (Ni, Co). ${ }^{[16-21]}$ Generally, cerium oxide (i) improves catalyst stability by preventing coke accumulation over the active metal surface, (ii) increases the catalytic activity by facilitating metal dispersion, and (iii) favors the activation of $\mathrm{CO}_{2}$.

As mentioned before, the $\mathrm{Ce}^{3+} / \mathrm{Ce}^{4+}$ redox couple is mainly responsible for the enhanced catalytic activity. However, understoichiometric $\mathrm{CeO}_{2-x}$ is mostly present in small nanoparticles with oxygen deficiency concentrated in low-coordinated cerium atoms on the surface. ${ }^{[22-25]}$ This implies that, in a ceria supported system, the amount of $\mathrm{Ce}^{3+}$ is proportional to the dispersion of the oxide. However, the reducibility of ceria in a redox environment will also influence its chemical state. In this sense, many attempts were made to describe the promoter effect of cerium oxide in the catalytic dry reforming of methane (DRM). ${ }^{[12,16,20,26-30]}$ Different characterization techniques have been utilized for that purpose, including temperature programmed reduction/oxidation (TPR/TPO), x-ray photoelectron spectroscopy (XPS) and x-ray absorption spectroscopy (XAS). ${ }^{6,8,20,26,27,31]} \mathrm{CeO}_{2-x}$ goes through reduction/oxidation cycles along the reaction, enhancing oxygen mobility and coke gasification, thus improving the catalyst stability. Accordingly, an intimate contact between ceria and the active metal phase (coke promoter) should facilitate the process, and this can be addressed by using a high surface support. ${ }^{[32-34]}$ On the other hand, a proper dispersion of the active metal phase has been shown to reduce graphitic coke formation by suppressing methane decomposition (the main source of coke at high temperatures), ${ }^{[35,36]}$ a structure-sensitive reaction which is favored in larger crystal. ${ }^{[37,38]}$ In this sense, several approaches has been explored to prevent metal aggregation as MgO-based solidsolution catalysts, ${ }^{[39-41]}$ mixed metal oxide materials (as perovskites) ${ }^{[42,43]}$ or co-impregnation with promoter oxides. ${ }^{[44-46]}$ Here, we studied five nickel-based systems promoted with cerium and supported in mesoporous silica SBA-15 for the DRM reaction. The catalysts were prepared by an ultrasonic-assisted incipient wetness impregnation method with different nickel loading and $\mathrm{Ni} / \mathrm{Ce}$ atomic ratio. Both total metal loading and cerium content influence the metal dispersion and catalytic activity. By using in situ spectroscopies, we have (i) correlated the cerium dispersion with the availability of $\mathrm{Ce}^{3+}$ on surface (XPS), and (ii) determined the physicochemical state of nickel (XAS) under reaction conditions. A higher dispersion of both nickel and ceria increased the catalytic activity and selectivity in DRM reducing the level of coke formation. On the other hand, the temperature programmed reduction profiles show the effect of metal loading in the reducibility of ceria which is the key in its promoting effect.

\section{Results and Discussion}




\section{Characterization of the calcined catalysts}

The characteristic textural and structural properties of the SBA-15 support are illustrated in Fig. S1. The $\mathrm{N}_{2}$-adsorption/desorption isotherm of the calcined SBA-15 shows a hysteresis behavior at a relative pressure $\left(p / p_{0}\right)$ higher than 0.45 , associated to a Type IV $(\mathrm{H} 1)$ ordered mesoporous material, ${ }^{[47]}$ which is preserved after impregnation and calcination of the metal nitrate precursors (see
Fig. S1a). Pore size distribution shows a main pore width of 6.5-8 $\mathrm{nm}$, the abundance of which decreases after metal loading. Moreover, the small-angle diffraction pattern (Fig. S1b) shows an intense peak at $0.93^{\circ}$ and two small ones at 1.64 and $1.89^{\circ}$, corresponding to the (100), (110) and (200) planes, respectively, associated to the two-dimensional hexagonal arrangement of SBA-15 which is clearly observed by TEM (Fig. S1c).

Table 1. Specific surface areas and pore volume obtained from $\mathrm{N}_{2}$ Adsorption/Desorption Isotherms, Ni and Ce weight percentage measured by ICP, average crystallite size by the Scherrer Equation, elemental atomic percentages calculated from XPS Spectra, and $\mathrm{H}_{2}$ consumption from a TPR experiment of the xNiyCe- supported in SBA-15 systems.

\begin{tabular}{|c|c|c|c|c|c|c|c|c|c|c|c|c|}
\hline \multirow[t]{2}{*}{$\begin{array}{l}\text { Catalyst } \\
\text { calcined at } \\
550^{\circ} \mathrm{C}\end{array}$} & \multirow[t]{2}{*}{$\begin{array}{l}S_{\text {BET }} / \\
m^{2} \cdot g^{-1}\end{array}$} & \multirow[t]{2}{*}{$\begin{array}{c}{ }^{[a]} V_{T} / \\
\mathrm{cm}^{3} \cdot \mathrm{g}^{-1}\end{array}$} & \multicolumn{2}{|c|}{ ICP / wt.\% } & \multicolumn{2}{|c|}{$\begin{array}{l}\text { Scherrer } \varnothing / \\
\mathrm{nm}\end{array}$} & \multicolumn{4}{|c|}{${ }^{[b]}\left[\mathrm{X}^{\mathrm{n}+}\right]_{\text {surface }} /$ at. $\%$} & \multicolumn{2}{|c|}{$\begin{array}{c}\mathbf{H}_{2} \text { consumption / } \\
\mathrm{mmol} \cdot \mathrm{g}^{-1}\end{array}$} \\
\hline & & & $\mathrm{Ni}$ & $\mathrm{Ce}$ & $\mathrm{NiO}$ & $\mathrm{CeO}_{2}$ & $\mathrm{Ni}$ & & $\mathrm{Si}$ & $\mathrm{O}$ & Total & ${ }^{\mathrm{c}} \mathrm{CeO}_{x}$ \\
\hline SBA-15 & 738 & 0.80 & - & - & - & - & - & & 32.5 & 63.6 & - & \\
\hline $5 \mathrm{Ni}-$ & 550 & 0.63 & 4.8 & - & 19 & - & 1.1 & - & 32.8 & 64.6 & 0.84 & - \\
\hline $10 \mathrm{Ni}-$ & 439 & 0.56 & 10.3 & - & 19 & - & 1.9 & - & 32.3 & 64.0 & 1.71 & - \\
\hline 5Ni9Ce- & 421 & 0.52 & 5.0 & 9.4 & n.d. & 3 & 0.9 & 0.8 & 31.7 & 64.9 & 1.47 & 0.62 \\
\hline 10Ni9Ce- & 377 & 0.46 & 9.9 & 9.2 & 15 & 4 & 2.1 & 1.2 & 30.7 & 62.5 & 2.20 & 0.50 \\
\hline 10Ni18Ce- & 314 & 0.36 & 9.5 & 19.0 & 37 & 6 & 2.3 & 1.0 & 30.9 & 63.5 & 2.13 & 0.43 \\
\hline
\end{tabular}

[a] $\mathrm{V}_{\mathrm{T}}$ symbol corresponds to the single point pore volume at $\mathrm{P} / \mathrm{P}_{0}=0.965$ of the nitrogen adsorption isotherm. [b] Calculated from the $\mathrm{XPS}$ spectra. [c] Calculation based on the total reduction of nickel.

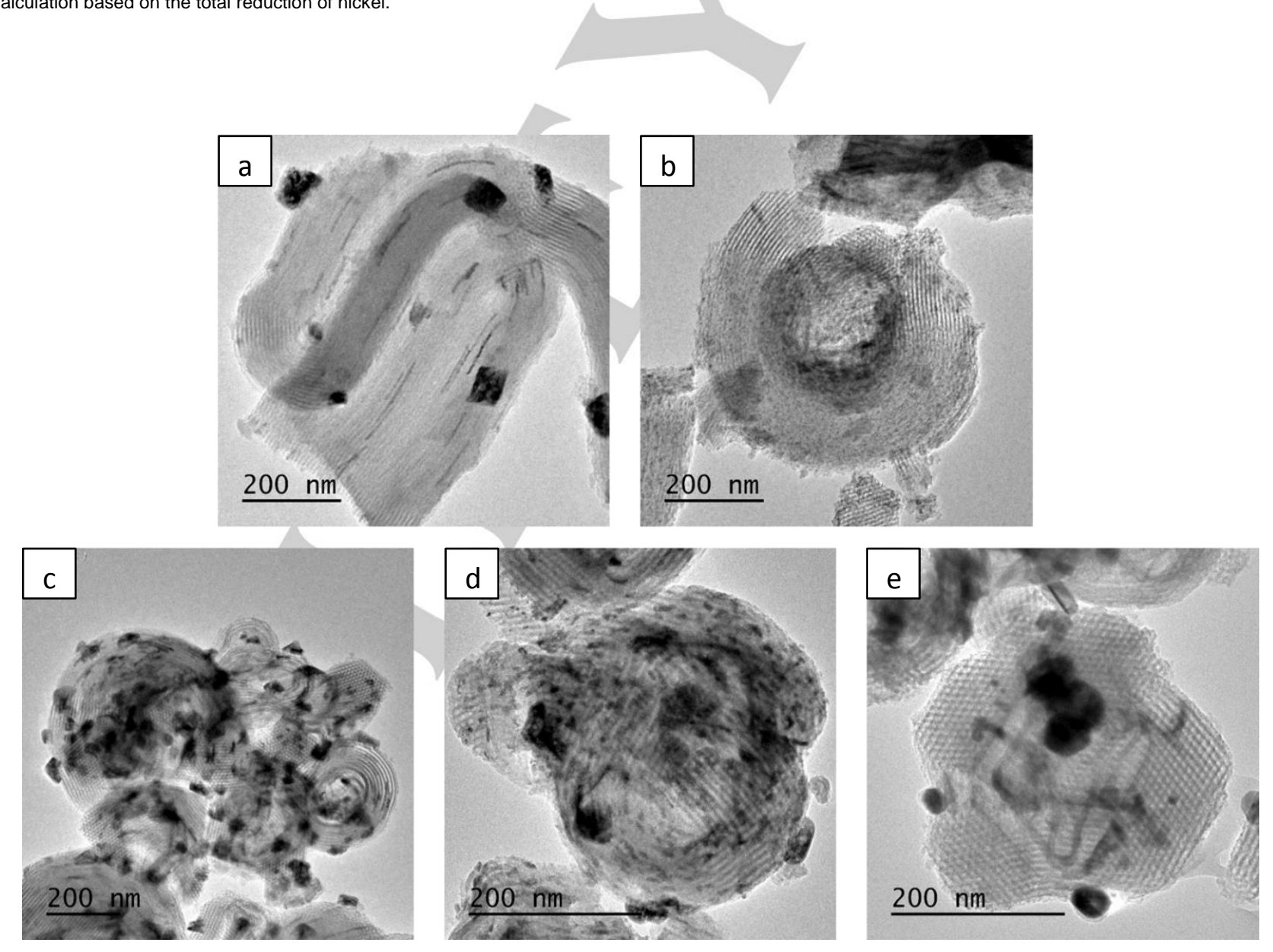

Figure 1. TEM images of as-made 5Ni- (a), 5Ni9Ce- (b), 10Ni- (c), 10Ni9Ce- (d) and 10Ni18Ce/SBA-15 (e). 
The five xNiyCe/SBA-15 catalysts were submitted to characterization by $\mathrm{N}_{2}$-adsorption analysis (BET, BJH), TEM, XRD, ICP, TPR, XPS and XAS. Some of the most characteristic physicochemical and textural properties of the catalysts are collected in Table 1. As shown, the specific surface area of the pristine SBA-15 decreased from 738 to $550-314 \mathrm{~m}^{2} \cdot \mathrm{g}^{-1}$ after impregnation of both nickel and cerium nitrate precursors and subsequent calcination, being progressively lower at higher nickel-cerium content. Similarly, the pore volume decreased from 0.80 to $0.63-0.36 \mathrm{~cm}^{3} \cdot \mathrm{g}^{-1}$. On the other hand, the TEM images in Fig. 1 show that the structure of SBA-15 is preserved after impregnation and calcination of metal salts which give rise to the partial occupation of the mesoporous channels by the nickelcerium phase that can be distinguish into dark aggregates. However, the distribution of the metallic phase depended on several factors: (i) the lower the nickel loading the better the metal dispersion, as can be seen in $5 \mathrm{Ni}$ - and $5 \mathrm{Ni9Ce} / \mathrm{SBA}-15$ samples (Fig. 1a and 1b, respectively). Moreover, (ii) the addition of cerium clearly improved the homogeneity of the catalytic systems, especially in $5 \mathrm{Ni9Ce} / \mathrm{SBA}-15$ which shows most of the metallic phase inside the mesoporous structure, but also in $10 \mathrm{Ni9Ce} / \mathrm{SBA}$ 15 compared to the analogous $10 \mathrm{Ni} / \mathrm{SBA}-15$ (Fig. 1d and 1c, respectively) which shows a higher concentration of outer large aggregates. Finally, (iii) an excess of cerium loading resulted in the aggregation of the metallic phase as shown in the image corresponding to the $10 \mathrm{Ni} 18 \mathrm{Ce} / \mathrm{SBA}-15$ sample (Fig. 1e).

The $\mathrm{x}$-ray diffraction diagrams in Fig. 2a display the formation of a $\mathrm{NiO}$ cubic phase in all the calcined catalysts as well as peaks associated with the fluorite-type structure of $\mathrm{CeO}_{2}$ in cerium doped systems. Interestingly, the $\mathrm{NiO}$ crystallite size estimated by the Scherrer equation decreased from $19 \mathrm{~nm}$, in both monometallic systems, to a not-determined value in $5 \mathrm{Ni9Ce} / \mathrm{SBA}$ 15 due to peaks width which indicates the generation of very small crystals, and to $15 \mathrm{~nm}$ in $10 \mathrm{Ni9Ce} / \mathrm{SBA}-15$. Besides, the average crystallite size of $\mathrm{NiO}$ at high cerium loading increased to $37 \mathrm{~nm}$. On the other hand, the $\mathrm{CeO}_{2}$ average crystallite sizes of 3,4 and $6 \mathrm{~nm}$ in $5 \mathrm{Ni9Ce}-10 \mathrm{Ni9Ce}-$ and $10 \mathrm{Ni} 18 \mathrm{Ce} / \mathrm{SBA}-15$, respectively, indicates a high dispersion of the ceria phase in the three bimetallic $\mathrm{Ni}-\mathrm{Ce}$ catalysts.

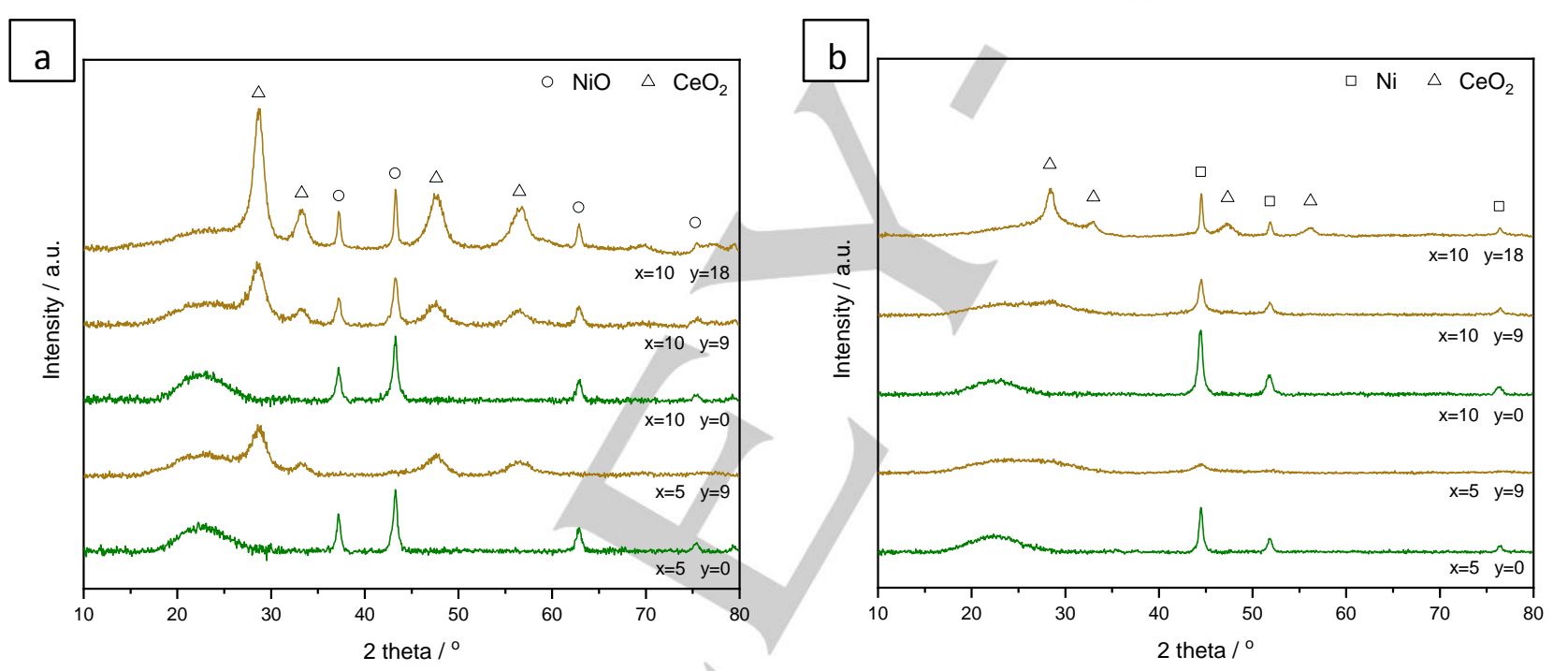

Figure 2. Powder x-ray diffractograms of the as-made (a) and reduced in a $5 \% \mathrm{H}_{2} / \mathrm{Ar}$ gas mixture at $750{ }^{\circ} \mathrm{C}$ (b) $\mathrm{xNiyCe} / \mathrm{SBA}-15 \mathrm{systems}$.

The reducibility of the calcined systems has been followed by temperature programmed reduction (TPR) measurements. According to the profiles shown in Fig. $3 a$, the monometallic systems present two main reduction processes with peaks centered at $340-370$ and ca. $520^{\circ} \mathrm{C}$. The first peak appears at the same temperature range of bulk $\mathrm{NiO}$ while the second one can be ascribed to $\mathrm{NiO}$ in a stronger interaction with the support, as expected for $\mathrm{NiO}$ clusters inside the channels of SBA-15. ${ }^{[48]}$ In most of the samples, the peak assigned to bulk $\mathrm{NiO}$ shows at least two components at ca. 314 and $365^{\circ} \mathrm{C}$ which would indicate different grades of $\mathrm{NiO}$ aggregation in surface of the support. This correlates with the highest prominence of the peak at lower temperature and the almost negligible component at ca. $500{ }^{\circ} \mathrm{C}$ in $10 \mathrm{Ni18Ce} / \mathrm{SBA}-15$ which shows a greater aggregation of the metallic phase (see Fig. 1e, TEM). Moreover, the peaks at 314 and $365^{\circ} \mathrm{C}$ have been shifted to 340 and $388^{\circ} \mathrm{C}$, respectively, in both $5 \mathrm{Ni9Ce}$ - and $10 \mathrm{Ni9Ce} / \mathrm{SBA}-15$ which can be ascribed to a more effective $\mathrm{NiO}-\mathrm{CeO}_{2}$ interaction. On the other hand, the reducibility of ceria must be taken into account for a complete interpretation of the TPR profiles. The reduction of massive ceria is expected at temperatures above $750^{\circ} \mathrm{C}$ while several authors have described the reduction of surface $\mathrm{CeO}_{x}$ species at low temperature $\left(>500{ }^{\circ} \mathrm{C}\right)$, in the same range of $\mathrm{NiO} \cdot{ }^{[49-51]} \mathrm{The} \mathrm{H}_{2}$ consumption in the partial reduction of ceria could be estimated by assuming the total transformation of $\mathrm{NiO}$ into metallic nickel along the TPR experiment. As shown in Table 1, a consumption of $0.62,0.50$ and $0.43 \mathrm{mmol} \cdot \mathrm{g}^{-1}$ of $\mathrm{H}_{2}$ is found for $5 \mathrm{Ni9}-, 10 \mathrm{Ni9Ce}$ and $10 \mathrm{Ni} 18 \mathrm{Ce} / \mathrm{SBA}-15$, respectively. According to the following reaction: $2 \mathrm{CeO}_{2}+\mathrm{H}_{2} \rightarrow \mathrm{Ce}_{2} \mathrm{O}_{3}+\mathrm{H}_{2} \mathrm{O}$, these values represent a reduction of 97,78 and $33 \%$ of the total $\mathrm{CeO}_{2}$ phase in each case. Fig. $3 \mathrm{~b}$ displays the $\mathrm{CO}_{2}$-TPD profiles of the xNiyCe/SBA-15 catalysts which accounts for the basicity of the samples. The presence of basic sites on the catalyst surface leads to a greater adsorption and activation of carbon dioxide which can react with 
$\mathrm{CH}_{\mathrm{x}}$ species but also with the carbon deposited on surface by the reverse Boudouard reaction $\left(\mathrm{C}+\mathrm{CO}_{2} \rightarrow 2 \mathrm{CO}\right)$. As seen, both monometallic catalysts show a negligible adsorption of carbon dioxide while the incorporation of ceria allows for better capacity, as the peaks in the $50-450{ }^{\circ} \mathrm{C}$ range show. Generally, the desorption of carbon dioxide at temperatures below $200{ }^{\circ} \mathrm{C}$ can be ascribed to a weak basicity, this being the case of the $5 \mathrm{Ni9Ce}$ and $10 \mathrm{Ni9Ce} / \mathrm{SBA}-15$ samples which show a main peak at $175^{\circ} \mathrm{C}$ and a secondary one at $90{ }^{\circ} \mathrm{C}$. In addition to the peaks at low temperature, the $10 \mathrm{Ni} 18 \mathrm{Ce} / \mathrm{SBA}-15$ exhibits a main peak at $260{ }^{\circ} \mathrm{C}$ with a wide shoulder up to $450{ }^{\circ} \mathrm{C}$ associated to the decomposition of carbonate species in moderate basic sites ${ }^{[52]}$ which is also present in $5 \mathrm{Ni9Ce} / \mathrm{SBA}-15$. Taking into account the relative intensity of the peaks and total adsorption of $\mathrm{CO}_{2}$, the order in basicity can be stablished as $10 \mathrm{Ni} 18 \mathrm{Ce}-\left(17.6 \mu \mathrm{mol} \cdot \mathrm{g}^{-1}\right)$ $>5 \mathrm{Ni9Ce}-\left(16.0 \mu \mathrm{mol} \cdot \mathrm{g}^{-1}\right)>10 \mathrm{Ni9Ce}-\left(7.9 \mu \mathrm{mol} \cdot \mathrm{g}^{-1}\right)>>5 \mathrm{Ni}-$ $\approx 10 \mathrm{Ni} / \mathrm{SBA}-15\left(>1 \mu \mathrm{mol} \cdot \mathrm{g}^{-1}\right)$.

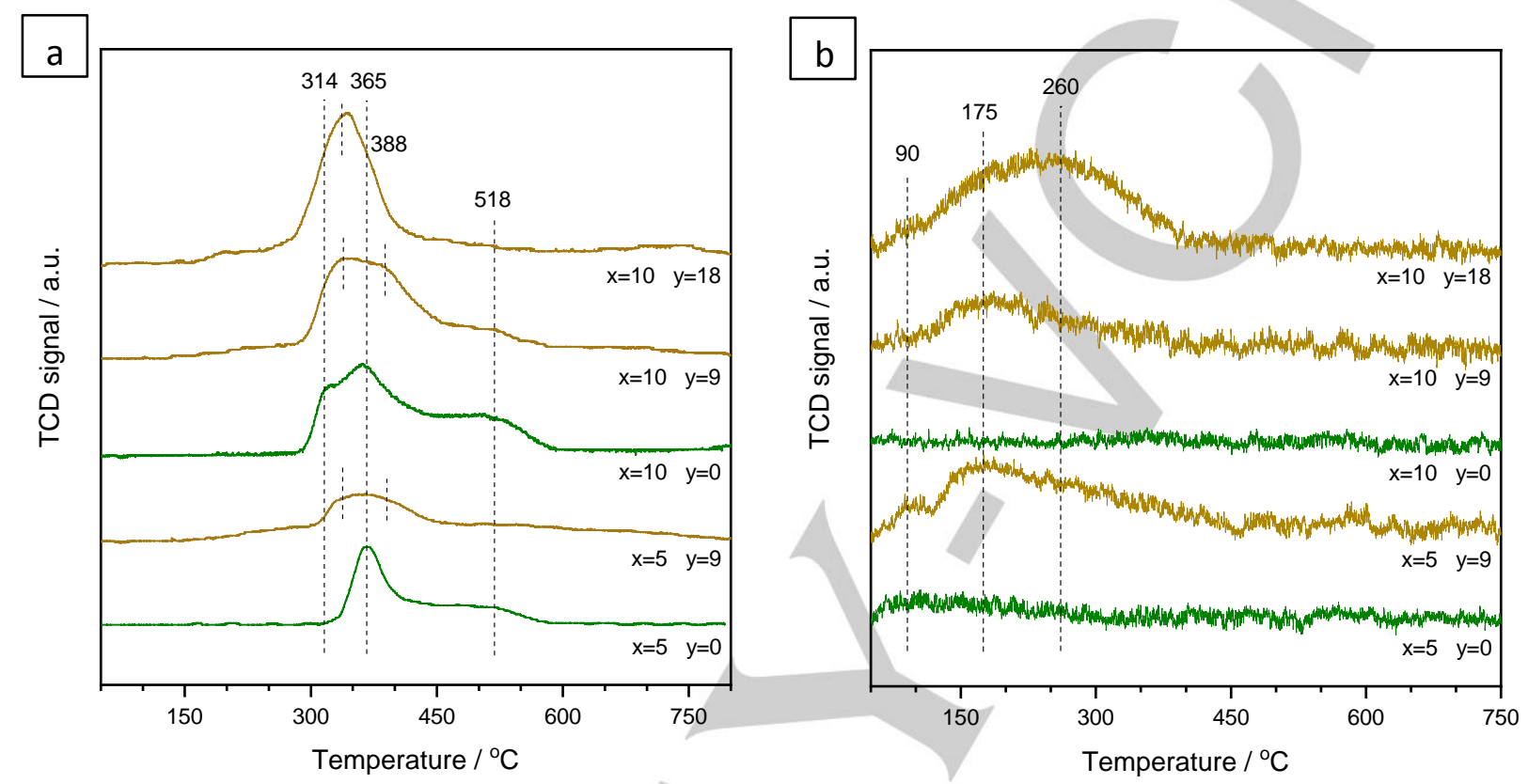

Figure 3 Temperature-programmed reduction profiles of the as-made $\mathrm{xNiyCe/SBA-15}$ systems (a) and temperature-programmed desorption of $\mathrm{CO}_{2}$ profiles of the pre-reduced catalysts (b).

Next, the physicochemical state of the calcined Ni-Ce bimetallic catalysts was analyzed by XPS. Fig. 4 plots the recorded signals of $\mathrm{Ce} 3 \mathrm{~d}$ and Ni2p regions. Despite the coupling between the $\mathrm{Ce} 3 d_{5 / 2}$ and $\mathrm{Ni} 2 \mathrm{p}_{1 / 2}$ signals, the well resolved $\mathrm{Ni} 2 \mathrm{p}_{3 / 2}$ peak with maximum at ca. $855 \mathrm{eV}$ can be assigned to $\mathrm{Ni}^{2+}$ (Fig. 4a). Meanwhile, the analysis of the Ce3d signal is rather complex due to (i) the coupling between $5 / 2$ and $3 / 2$ spin-orbit split components, (ii) the co-existence of both $\mathrm{Ce}^{3+}$ and $\mathrm{Ce}^{4+}$ associated electronic configurations, and (iii) the $\mathrm{Ni}_{2} \mathrm{p}_{1 / 2}$ interference at lower binding energy. With the aim of estimating the $\mathrm{Ce}^{3+} /\left(\mathrm{Ce}^{3+}+\mathrm{Ce}^{4+}\right)$ atomic ratio on catalyst surface, the $\mathrm{Ce} 3 \mathrm{~d}$ signal envelope was constructed using a Shirley background and symmetric GaussianLorentzian functions for each component. The analysis was done using the nomenclature given by Burroughs et al. ${ }^{[53]}$ (see Fig. 4b), commonly applied by other authors in cerium based systems. ${ }^{[54-}$ ${ }^{57]}$ Accordingly, the $\mathrm{Ce}^{3+} /\left(\mathrm{Ce}^{3+}+\mathrm{Ce}^{4+}\right)$ ratio is given by the following equation:

$$
\frac{C e^{3+}}{C e^{3+}+C e^{4+}}=\frac{v^{0}+v^{\prime}+u^{0}+u^{\prime}}{v^{0}+v^{\prime}+u^{0}+u^{\prime}+v+v^{\prime \prime}+v^{\prime \prime \prime}+u+u^{\prime \prime}+u^{\prime \prime \prime}}
$$



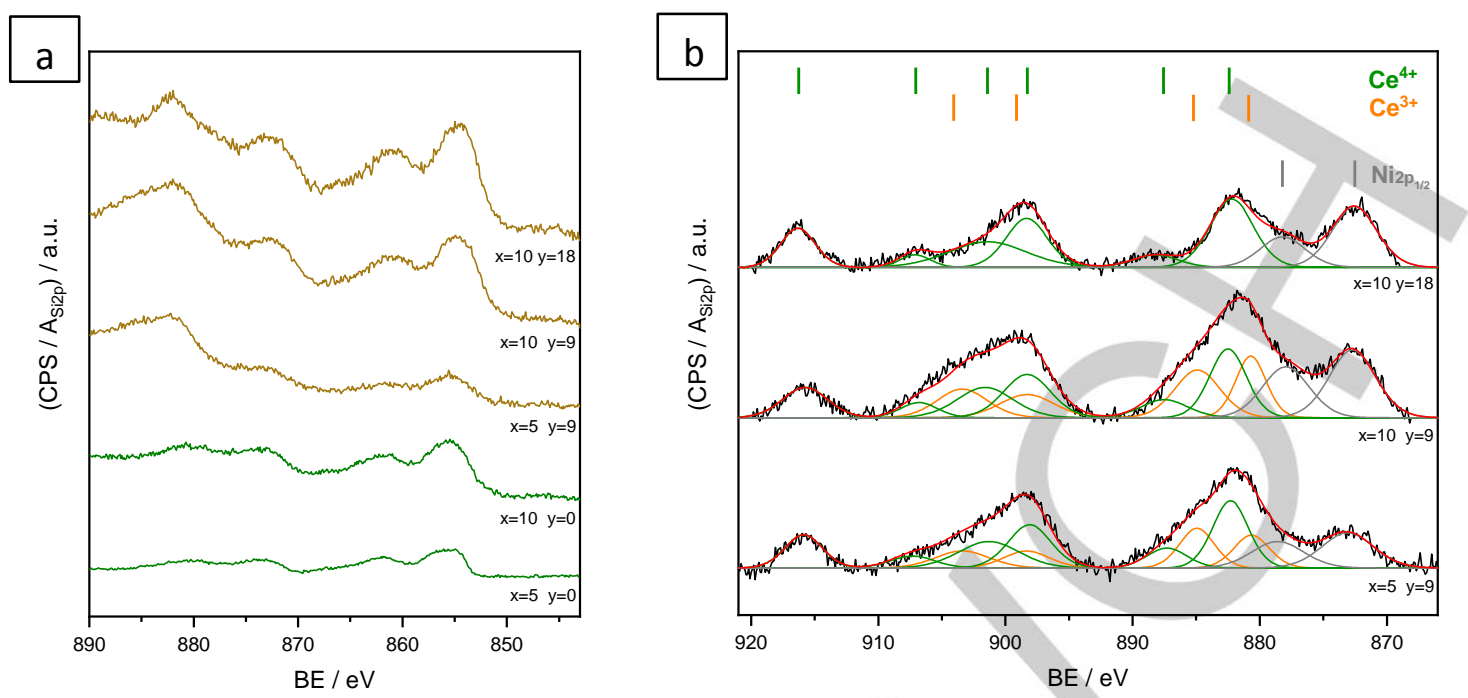

Figure 4. XPS spectra of the as-made XNiyCe/SBA-15 systems in the $\mathrm{Ni} 2 \mathrm{p}(\mathrm{a})$ and $\mathrm{Ce} 3 \mathrm{~d}$ (b) regions. $\mathrm{Ce}^{4+}, \mathrm{Ce}^{3+}$ and Ni $2 \mathrm{p}_{1 / 2}$ contributions are colored in green, orange and gray, respectively. Red line represents the fitted peaks envelope.

This way, values of $0.33,0.43$ and 0 were estimated for the $5 \mathrm{Ni9Ce}-$, 10Ni9Ce- and 10Ni18Ce/SBA-15 catalysts, respectively. According to the given ratios, both $5 \mathrm{Ni} 9 \mathrm{Ce}-$ and $10 \mathrm{Ni} 9 \mathrm{Ce} / \mathrm{SBA}-15$ catalysts present a high concentration of $\mathrm{Ce}^{3+}$ on surface which has been directly associated to the availability of low-coordinated cerium atoms on edge sites, as expected in very small ceria nanoparticles. ${ }^{[58]}$ A higher concentration of these sites has been found to enhance the catalytic activity in redox reactions. ${ }^{[59]}$ Finally, the calcined systems were also analyzed by XAS in the $\mathrm{Ni}$ K-edge region. As shown in Fig. 5a, all the samples present the typical XANES features of a cubic $\mathrm{NiO}$ reference with the maximum being the white line at $8350 \mathrm{eV}$. On the other hand, Fourier Transforms of the EXAFS region included in Fig. 5b (with phase correction) display two main peaks at low radial distances corresponding to $\mathrm{Ni}-\mathrm{O}_{1}(1.9 \AA)$ and $\mathrm{Ni}-\mathrm{Ni}_{2}(2.8 \AA)$, first and second coordination sphere, respectively. $A$ decrease of the $\mathrm{Ni}_{-} \mathrm{Ni}_{2}$ amplitude could indicate a distortion of the $\mathrm{NiO}$ lattice thus annulling the strong multiple scattering effect for paths involving collinear atoms in the cubic phase. ${ }^{[60,61]}$ This is found in the $5 \mathrm{Ni9Ce} / \mathrm{SBA}-15$ sample, either owing to the small $\mathrm{NiO}$ crystallite size or to the incorporation of cerium in the structure.
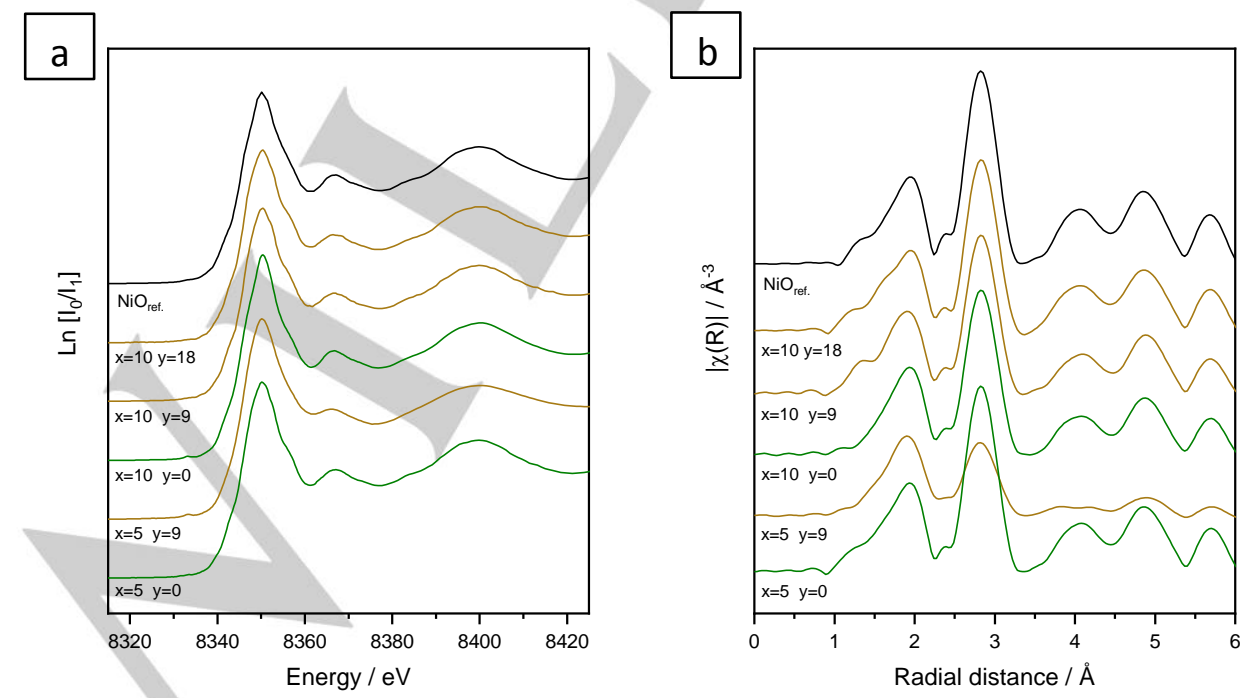

Figure 5. Ni-K edge XANES spectra (a) and Fourier transform functions of the EXAFS oscillations (b) of the calcined xNiyCe/SBA-15 systems. 


\section{In situ XPS and XAS study under reduction conditions}

The Ni-Ce systems have been studied in situ by XPS and XAS under reduction conditions. The spectra were collected using a $5 \% \mathrm{H}_{2} / \mathrm{Ar}$ flow from room temperature (RT) up to $750{ }^{\circ} \mathrm{C}$, mimicking the pre-treatment conditions before catalytic test (vide supra). Fig. 6 shows the high-resolution spectra of the Ce3d and $\mathrm{Ni} 2 \mathrm{p}$ regions after the treatment in a $5 \% \mathrm{H}_{2} / \mathrm{Ar}$ mixture at $750{ }^{\circ} \mathrm{C}$. At these conditions, nickel has been totally reduced to $\mathrm{Ni}^{0}$ with a maximum of the $\mathrm{Ni}_{2} \mathrm{p}_{3 / 2}$ signal at $851.7 \mathrm{eV}$ (Fig. 6a). Moreover, most of the cerium presents $\mathrm{a}+3$ oxidation state in the three $\mathrm{Ni}$ Ce bimetallic catalysts (Fig. 6b) while the components associated to $\mathrm{Ce}^{4+}$ are only relatively intense in the $10 \mathrm{Ni} 18 \mathrm{Ce} / \mathrm{SBA}-15$ sample, representing ca. $15 \%$ of the total cerium on surface (see Table 2). Similarly, the XRD pattern of the reduced samples included in Fig. $2 \mathrm{~b}$ show peaks associated to metallic nickel in all the cases while the peaks associated to $\mathrm{CeO}_{2}$ are almost negligible, except in the $10 \mathrm{Ni} 18 \mathrm{Ce} / \mathrm{SBA}-15$ sample. Interestingly, the intensity of both $\mathrm{Ni} 2 \mathrm{p}$ and $\mathrm{Ce} 3 \mathrm{~d}$ spectra increases at higher total metal loading in analogous systems (i.e., 10Ni18Ce > $10 \mathrm{Ni}(9 \mathrm{Ce})$, and $10 \mathrm{Ni9Ce}>5 \mathrm{Ni9Ce}$, respectively) while both XRD and TEM (Fig. S2) results indicate the opposite, i.e. the higher the $\mathrm{Ni}-\mathrm{Ce}$ loading the lower the metal dispersion. This has already been explained by our group as an effect of metal location inside the mesopores of SBA-15 which make it invisible to XPS. ${ }^{[48]}$ As shown by TEM images of the reduced samples (Fig. S2), most of the bimetallic nanoparticles obtained after reduction of $5 \mathrm{Ni9Ce} / \mathrm{SBA}-15$ are aligned with the well-defined channels of the support.
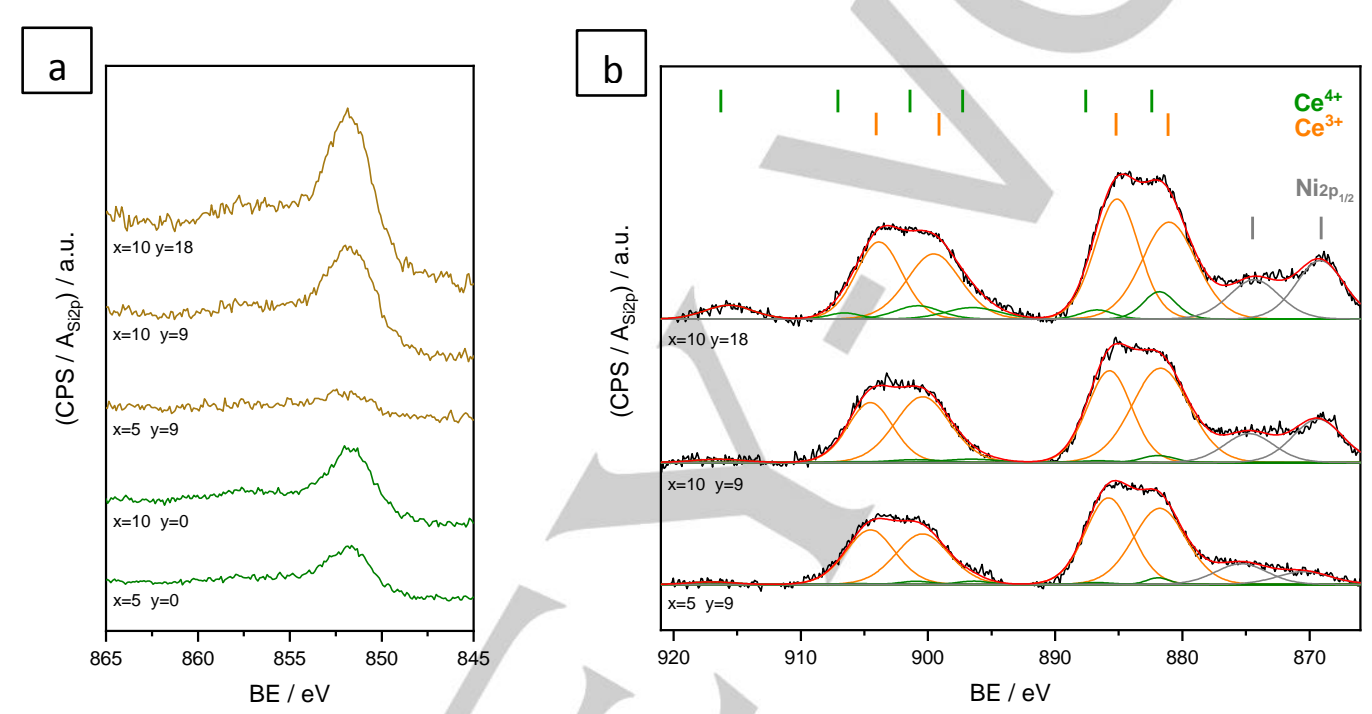

Figure 6. XPS spectra of the reduced $x$ NiyCe/SBA-15 systems in the $\mathrm{Ni} 2 \mathrm{p}$ (a) and Ce $3 \mathrm{~d}$ (b) regions. $\mathrm{Ce}^{4+}, \mathrm{Ce}^{3+}$ and Ni $2 \mathrm{p}_{1 / 2} \mathrm{Components}$ are colored in green, orange and gray, respectively. Red line represents the fitted peaks envelope.

Fig. 7 shows the in situ XAS analysis of the catalysts submitted to hydrogen treatment at 500 and $750{ }^{\circ} \mathrm{C}$. The XANES spectra of the catalysts after treatment at $500{ }^{\circ} \mathrm{C}$ (Fig. 7a) show similar features to a nickel foil reference but with some changes in the white line $(8349 \mathrm{eV})$, particularly in its relative intensity, which indicates the dominance of nickel oxide. A lineal combination fitting of the spectra shows the remanence of $\mathrm{Ni}^{2+}$ in a 22, 29, 12 , 14 and $6 \%$ for $5 \mathrm{Ni}-$, $5 \mathrm{Ni9Ce}-, 10 \mathrm{Ni}-, 10 \mathrm{Ni9Ce}-$ and $10 \mathrm{Ni} 18 \mathrm{Ce} / \mathrm{SBA}-15$, respectively, i.e. it increases in the same way as nickel dispersion. Next, the treatment at $750^{\circ} \mathrm{C}$ gives rise the complete reduction of nickel in all the samples, as can be seen in both XANES and FT of EXAFS spectra displayed in Fig. 7b-c, showing a maximum in amplitude of the first coordination sphere at $2.46 \AA\left(\mathrm{Ni}_{-}-\mathrm{Ni}_{1}\right)$. The analysis of the radial distribution pseudofunction, based on FEFF calculations from a metallic nickel reference (fcc), provides information about the $\mathrm{Ni}-\mathrm{Ni}_{1}$ coordination number $(\mathrm{CN})$ which can be correlated with the nickel particle size since the contribution of low-coordinated surface atoms in nanoparticles gives rise to an average $\mathrm{CN}$ appreciably lower than 12 (bulk nickel). ${ }^{[62]}$ Taking into account the temperature dependence of the Debye-Waller factor, the fitting analysis were done over the recorded spectra at room temperature (Fig. 7c) while $\mathrm{CN}$ was estimated from the $\mathrm{Ni}-\mathrm{Ni}_{1}$ amplitude of a $\mathrm{Ni}$ foil reference $(\mathrm{CN}=12)$. This way, it has been estimated a $\mathrm{CN}$ of 11.0 , $10.1,11.2,10.8,11.8$ for $5 \mathrm{Ni}-, 5 \mathrm{Ni9Ce}-, 10 \mathrm{Ni}-, 10 \mathrm{Ni} 9 \mathrm{Ce}-$ and $10 \mathrm{Ni} 18 \mathrm{Ce} / \mathrm{SBA}-15$, respectively. In a model of pseudo-spherical particles, a $\mathrm{CN}$ in the 10-10.5 range would correspond to average particle sizes of $2-4 \mathrm{~nm}$ while $\mathrm{CN}>11.5$ is associated to particle sizes above $10 \mathrm{~nm} \cdot{ }^{[63,64]}$ The details of the fitting parameters for both XANES and EXAFS regions are recorded in Table 2. 

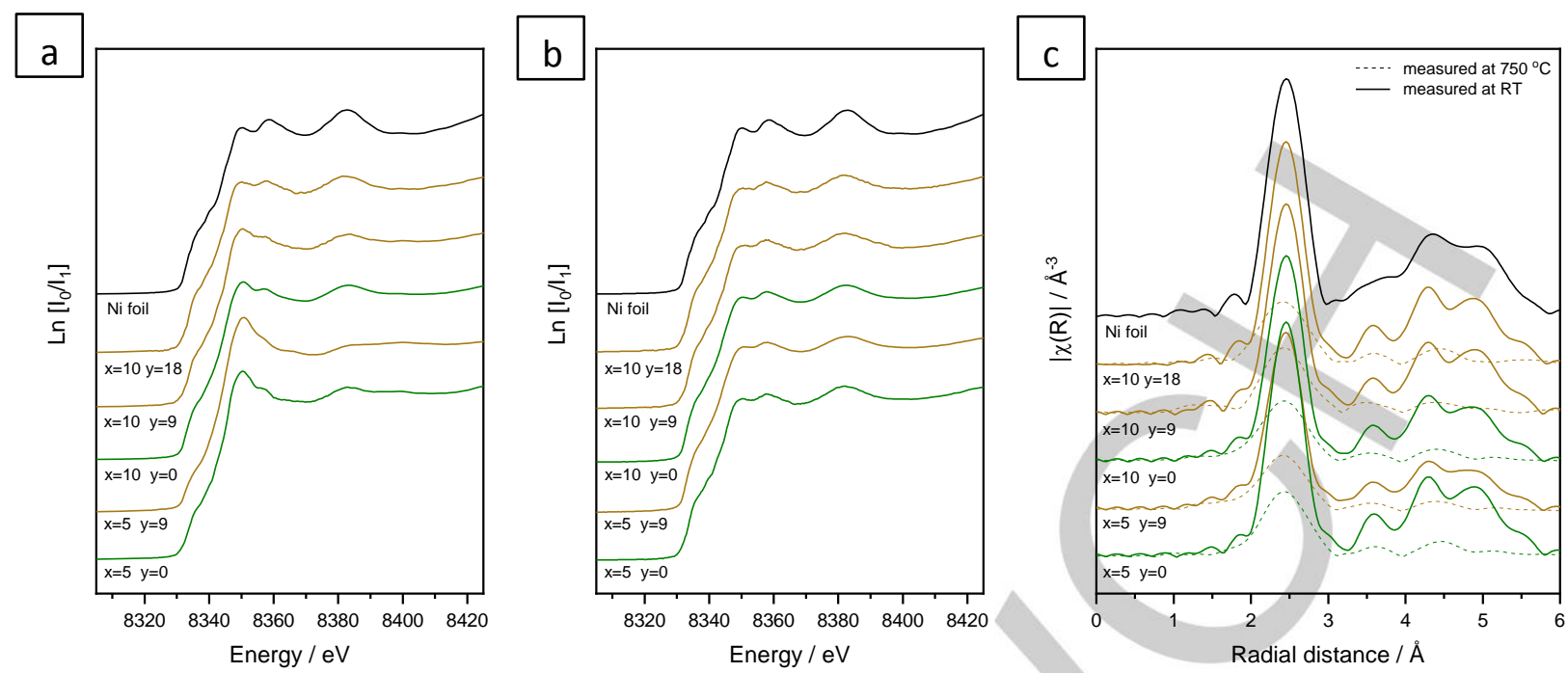

Figure $7 \mathrm{Ni}-\mathrm{K}$ edge XANES spectra of the reduced $\mathrm{XNiyCe} / \mathrm{SBA}-15$ catalysts at 500 (a) and $750{ }^{\circ} \mathrm{C}$ (b), and Fourier transform functions of the EXAFS oscillations (c) after reduction at $750{ }^{\circ} \mathrm{C}$.

As an initial summary, it can be rated that both the lower metal loading and cerium doping improved the nickel dispersion as shown by TEM (Fig. 1) and XRD (Fig. 2). This resulted in a lower reducibility of the nickel oxide phase and the formation of smaller nickel particles after total reduction at $750{ }^{\circ} \mathrm{C}$, as indicated the analysis of the average coordination number by XAS. $\mathrm{CO}_{2}$ TPD experiments has proven the role of ceria in the greater $\mathrm{CO}_{2}$ adsorption capacity, especially at the highest cerium loading. On the other hand, it has been observed that both the dispersion and reducibility of ceria improve at lower $\mathrm{Ni}$-Ce content. A consequence of this high dispersion is the presence of lowcoordinated $\mathrm{Ce}^{3+}$ species on surface in both $5 \mathrm{Ni9Ce}-$ and $10 \mathrm{Ni9Ce}$ calcined systems (Fig. 4b) which presumably is key in its promotional effect under reaction conditions. This will be examined with the catalytic results.

Table 2. $\mathrm{Ce}^{3+}$ concentration on surface estimated from the fitting of the $\mathrm{Ce} 3 \mathrm{~d}$ XPS signal, nickel oxide percentage calculated from the Ni-K edge XANES spectra, Best Fitting Values obtained from the FT of the Ni-K edge EXAFS spectra of the catalysts reduced at $750^{\circ} \mathrm{C}$ and average particle size estimated by TEM.

\begin{tabular}{|c|c|c|c|c|c|c|c|c|c|}
\hline \multirow{2}{*}{ Catalyst } & \multicolumn{2}{|c|}{$\mathrm{Ce}^{3+} /\left(\mathrm{Ce}^{3+}+\mathrm{Ce}^{4+}\right)^{[\mathrm{a}]}$} & \multicolumn{2}{|c|}{$\mathrm{NiO} \%{ }^{[b]}$} & \multicolumn{4}{|c|}{ Best-fit values from EXAFS of reduced samples ${ }^{[c]}$} & \multirow{2}{*}{$\begin{array}{l}\text { Average Ni particle } \\
\text { size / } \mathrm{nm}^{[\mathrm{d}]}\end{array}$} \\
\hline & Calcined & $\mathrm{H}_{2}, 750^{\circ} \mathrm{C}$ & $\mathrm{H}_{2}, 500{ }^{\circ} \mathrm{C}$ & $\mathrm{H}_{2}, 750^{\circ} \mathrm{C}$ & $\mathrm{CN}$ & $\Delta \mathrm{E}^{0}$ & $\mathrm{R}$ & $D-W\left(\AA^{2} \times 10^{-3}\right)$ & \\
\hline $5 \mathrm{Ni}-$ & - & - & 22 & 0 & 11.0 & 7.0 & 2.48 & 6.5 & 10.9 \\
\hline $10 \mathrm{Ni}-$ & - & - & 12 & 0 & 11.2 & 7.0 & 2.48 & 6.5 & 11.1 \\
\hline $5 \mathrm{Ni9Ce}-$ & 33 & 98 & 29 & 0 & 10.1 & 6.7 & 2.48 & 7.0 & 2.6 \\
\hline 10Ni9Ce- & 43 & 97 & 15 & 0 & 10.8 & 6.8 & 2.48 & 5.9 & 6.1 \\
\hline 10Ni18Ce- & 0 & 85 & 6 & 0 & 11.8 & 6.7 & 2.48 & 5.9 & 14.6 \\
\hline
\end{tabular}

[a] Estimated from the Ce 3d XPS signal analysis. [b] Calculated by linear combination of XANES spectra. [c] Measured at RT after reduction and referred to $\mathrm{CN}=12$ and $\mathrm{R}=2.48 \AA$ A of a reference Ni foil. [d] Calculated from the TEM histograms of reduced samples (Fig. S2).

\section{Catalytic studies}

The five catalysts were evaluated at $750{ }^{\circ} \mathrm{C}$ using a $1 / 1 / 1$ $\mathrm{CH}_{4}: \mathrm{CO}_{2}: \mathrm{N}_{2}$ gas mixture at atmospheric pressure, where the equilibrium conversion of $\mathrm{CH}_{4}$ and $\mathrm{CO}_{2}$ is ca. 90 and $95 \%$, respectively. ${ }^{[65,66]}$ Thus, the residence time effect was previously evaluated to work below thermodynamic control. As shown in Fig. 8 , the activity differs drastically between monometallic and cerium-doped systems. Initially, the conversion of methane (Fig.
8 a) reaches $80 \%$ in both $5 \mathrm{Ni9Ce}$ - and $10 \mathrm{Ni9Ce} / \mathrm{SBA}-15,70 \%$ for $10 \mathrm{Ni} 18 \mathrm{Ce} / \mathrm{SBA}-15$ catalyst, while it barely reaches $50 \%$ in both monometallic catalysts. These results can be expressed as a function of nickel loading which underlines that methane reaction rate $\left(\mathrm{mol} \mathrm{CH} \mathrm{CH}_{4} \cdot \mathrm{g}^{-1} \mathrm{Ni}\right.$ per hour, Fig. $\left.8 \mathrm{~b}\right)$ is improved at lower metal loading with values of 8 and $13 \mathrm{~mol} \cdot \mathrm{gNi}^{-1} \cdot \mathrm{h}^{-1}$ in both $5 \mathrm{Ni}$ - and $5 \mathrm{Ni9Ce} / \mathrm{SBA}-15$, respectively, doubling the measured values of the analogous 10Ni- and 10Ni9Ce-SBA-15. On the other hand, the effect of cerium is also reflected in a higher reaction rate. The greater activity seems to correlate in both cases to the better nickel dispersion. 

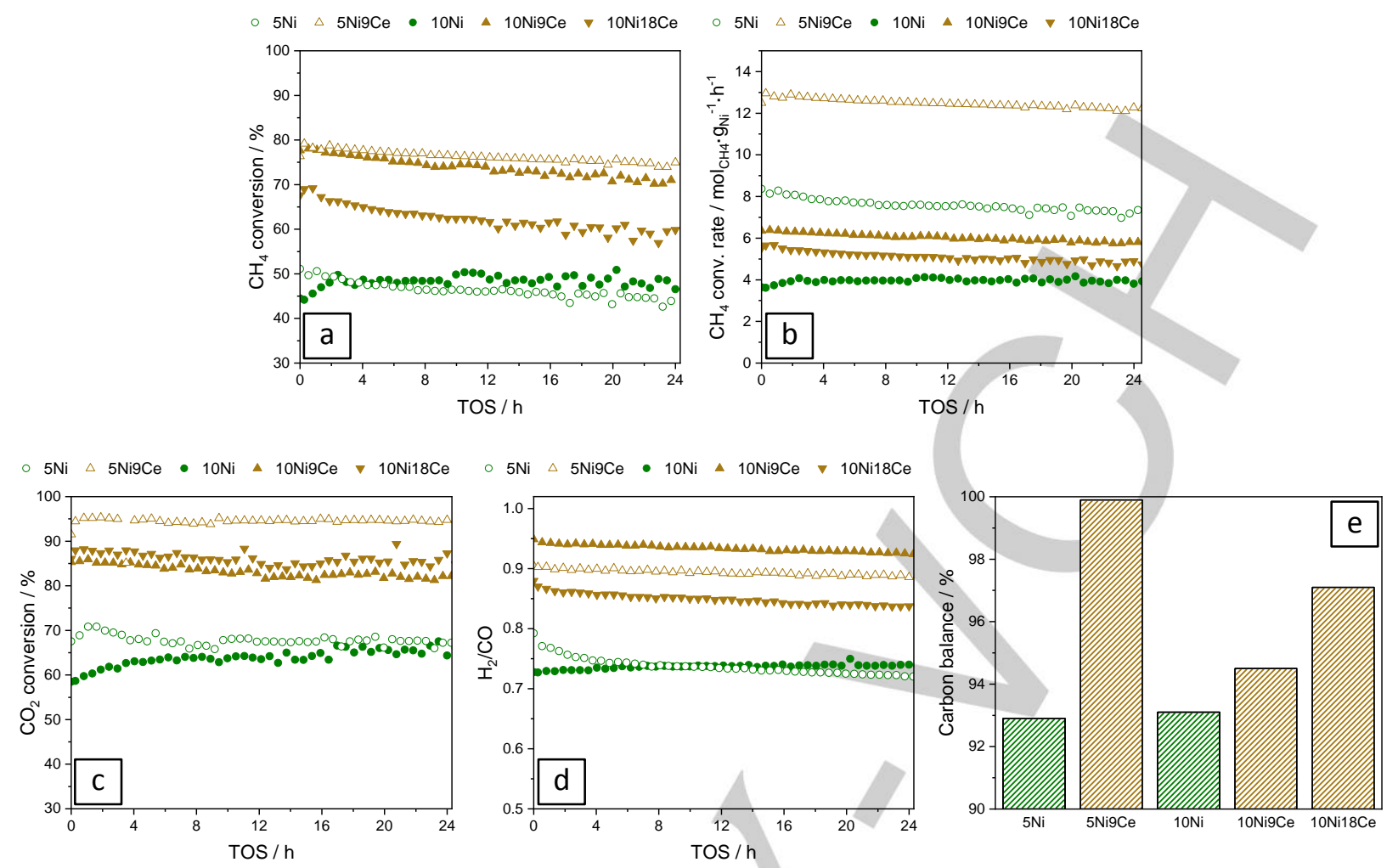

Figure $8 \mathrm{CH}_{4}$ conversion (a) and reaction rate (b), $\mathrm{CO}_{2}$ conversion (c), $\mathrm{H}_{2} / \mathrm{CO}$ ratio (d) and average carbon balance in gas phase (e) of the xNiyCe/SBA- 15 catalysts in the DRM reaction at $750^{\circ} \mathrm{C}$ and WHSV $=60000 \mathrm{~mL} \cdot \mathrm{min}^{-1} \cdot \mathrm{gcat}^{-1}$ for 24 hours.

The stability was examined throughout the 24 hours of reaction. The more active bimetallic $5 \mathrm{Ni9Ce}-, 10 \mathrm{Ni9Ce}-$ and $10 \mathrm{Ni} 18 \mathrm{Ce} / \mathrm{SBA}-15$ catalysts displayed a decrease of 6,11 and $15 \%$ in methane conversion, respectively. The lower deactivation rate in the $5 \mathrm{Ni}$ - and $10 \mathrm{Ni} / \mathrm{SBA}-15$ catalysts can be ascribed to their lower activity. On the other hand, the $\mathrm{H}_{2} / \mathrm{CO}$ ratio (Fig. $8 \mathrm{~d}$ ) was clearly improved by cerium, with values of ca. $0.9,0.95$ and 0.85 in the bimetallic $5 \mathrm{Ni9Ce}-$, $10 \mathrm{Ni9Ce}$ - and $10 \mathrm{Ni18Ce} / \mathrm{SBA}-15$ samples, respectively, being lower than 0.75 in both monometallic systems indicating a high reverse water-gas shift activity $\left(\mathrm{CO}_{2}+\mathrm{H}_{2} \rightarrow \mathrm{CO}+\mathrm{H}_{2} \mathrm{O}\right)$. Moreover, the carbon balance in gas phase (Fig. $8 \mathrm{e}$ ) is closed above $90 \%$ in all the cases but clearly improved at higher $\mathrm{Ce} / \mathrm{Ni}$ ratio, achieving a $99.9 \%$ in the $5 \mathrm{Ni9Ce} / \mathrm{SBA}-15$ catalyst. The latter shows a higher $\mathrm{CO}_{2}$ conversion (Fig. 8c) compared with the analogous $10 \mathrm{Ni9Ce} / \mathrm{SBA}-15$ sample ( 95 and $85 \%$, respectively), presumably toward CO thus lowering the $\mathrm{H}_{2} / \mathrm{CO}$ ratio. Therefore, it can be stablished that ceria improves the carbon balance by preventing coke formation nevertheless a high $\mathrm{Ce} / \mathrm{Ni}$ ratio can be detrimental by improving $\mathrm{CO}_{2}$ activation toward secondary reactions (as RWGS). Despite the above, the effect of particle size in coke formation should not be neglected since it has been seen that only large nickel particles, generally bigger than 5-7 nm, are responsible for the formation of filamentous carbon. ${ }^{[67-69]}$

Additionally, the XPS C 1s signal of the samples submitted to the in situ DRM reaction (see Fig. S3) shows two main components at 284.6 and ca. $281 \mathrm{eV}$, typically associated with C-C species and metal carbide, respectively. The first dominates in both $10 \mathrm{Ni}$ and $10 \mathrm{Ni} 18 \mathrm{Ce} / \mathrm{SBA}-15$ catalysts while the carbide contribution is only visible in the cerium-doped systems, relatively intense in the $10 \mathrm{Ni9Ce} / \mathrm{SBA}-15$ and almost negligible in both $5 \mathrm{Ni9Ce}-$ and $10 \mathrm{Ni} 18 \mathrm{Ce} / \mathrm{SBA}-15$ catalysts. In line with this, the XRD patterns of the spent samples (Fig. S4) show intense peaks associated with graphite in the monometallic 10Ni/SBA-15 catalyst which decrease at higher $\mathrm{Ce} / \mathrm{Ni}$ ratio. It could be hypothesized that cerium prevents the formation of $\mathrm{C}-\mathrm{C}$ bonds which occurs by a metal carbide intermediate (see Scheme 1). In fact, this mechanism has been already proposed for the methane decomposition reaction, ${ }^{[70-72]}$ main source of coke at these reaction conditions, which is favored in larger nickel aggregates (as in the case of $10 \mathrm{Ni}$ - and $10 \mathrm{Ni} 18 \mathrm{Ce} / \mathrm{SBA}-15$ samples). ${ }^{[37,38]}$ 


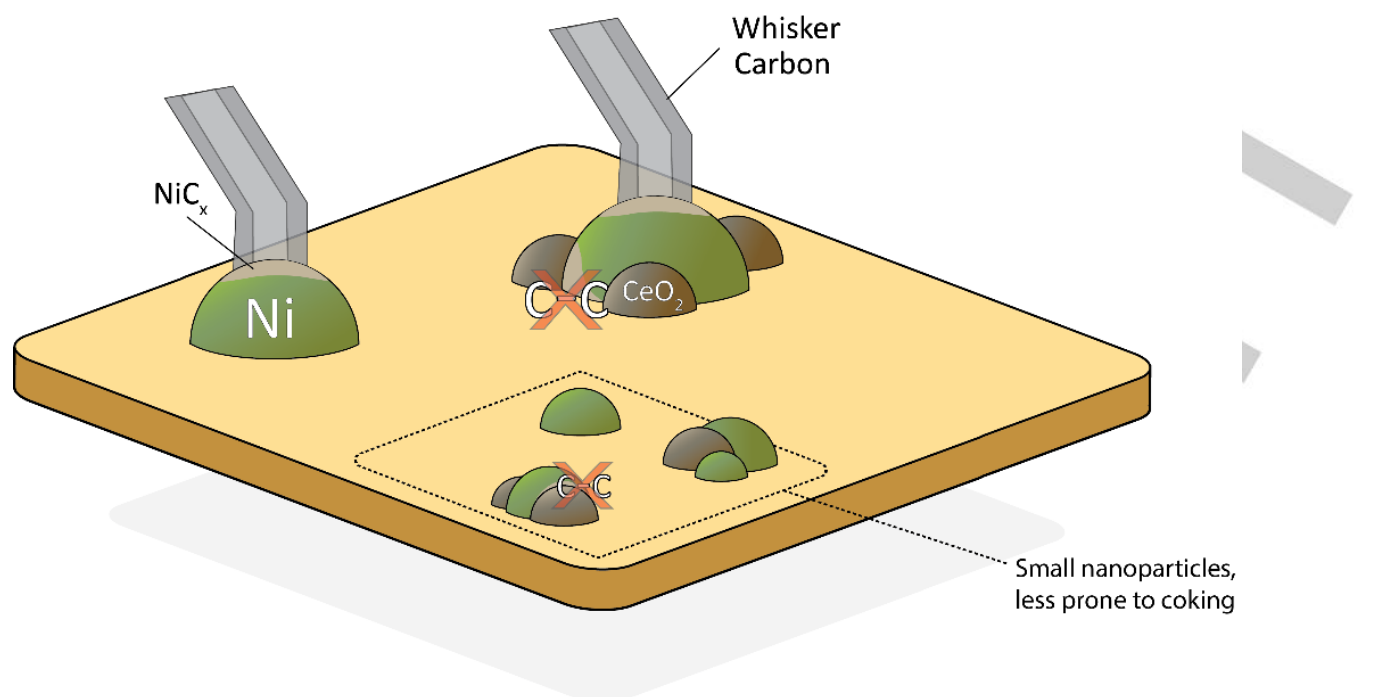

Scheme 1. Proposed mechanism for coke suppression by ceria during the DRM reaction. The structure-sensitive methane decomposition reaction over nickel gives rise to the formation of whisker carbon which grows from a $\mathrm{NiC}_{\mathrm{x}}$ intermediate. Ceria nanoparticles in direct contact with carbide species prevents $\mathrm{C}-\mathrm{C}$ propagation through the $\mathrm{CO}_{2}$ activation.

\section{Conclusion}

In summary, we have characterized a series of nickel-based catalysts promoted with ceria prepared by incipient wetness coimpregnation of SBA-15. Altogether, our results demonstrate that: (i) both lower metal loading and co-impregnation of cerium improved metal dispersion inside the mesoporous structure of SBA-15; (ii) the nickel resistance to reduction is improved at higher metal dispersion giving rise to smaller particles after a $5 \%$ $\mathrm{H}_{2} / \mathrm{Ar}$ treatment at $750{ }^{\circ} \mathrm{C}$. Conversely, ceria reducibility was improved; (iii) the promotional effect of ceria was clearly demonstrated during the catalytic tests by improving the $\mathrm{H}_{2} / \mathrm{CO}$ ratio and carbon balance. On the other hand, the enhanced $\mathrm{CO}_{2}$ activation by ceria $\left(\mathrm{CO}_{2}\right.$-TPD) can also promote undesirable secondary reaction as RWGS. Therefore, the $\mathrm{Ce} / \mathrm{Ni}$ has to be properly adjusted.

Finally, in view of the catalytic results and the in situ C 1s XPS analysis of the spent catalysts we proposed a reaction mechanism where ceria avoids coke formation by suppressing the propagation of $\mathrm{C}-\mathrm{C}$ bonds chain from a nickel carbide intermediate, precursor of filamentous carbon over metallic nickel surfaces.

\section{Experimental Section}

Catalysts preparation. SBA-15 mesoporous silica support was prepared according to the protocol reported by our group, ${ }^{[48]}$ based in Zhao's novel work published in 1998. ${ }^{[73]}$ Typically, $3 \mathrm{~g}$ of P123 (Sigma-Aldrich, CAS: 9003-11-6) was dissolved in $140 \mathrm{~mL}$ of hydrochloric acid $1.8 \mathrm{M}$ and heated up to $45^{\circ} \mathrm{C}$. Then, $5.9 \mathrm{~mL}$ of tetraethyl orthosilicate (Sigma-Aldrich, CAS: 78-10-4) was added to the solution reveling the formation of a white dispersion. After an aging period of $18 \mathrm{~h}$ at $45{ }^{\circ} \mathrm{C}$, the resulted white product was filtered in a Büchner funnel, washed with enough boiling water to completely remove the surfactant, dried at $150{ }^{\circ} \mathrm{C}$ and calcined for $3 \mathrm{~h}$ at the temperature of $550{ }^{\circ} \mathrm{C}$ using a ramp of $1^{\circ} \mathrm{C} \cdot \mathrm{min}^{-1}$. The nickel and cerium metal phases were loaded on $1 \mathrm{~g}$ of as-made SBA-15 by an ultrasonic-assisted incipient wetness impregnation method using $\mathrm{Ni}\left(\mathrm{NO}_{3}\right)_{2} \cdot 6 \mathrm{H}_{2} \mathrm{O}$ (Panreac, CAS: $\left.13478-00-7\right)$ and $\mathrm{Ce}\left(\mathrm{NO}_{3}\right)_{3} \cdot 6 \mathrm{H}_{2} \mathrm{O}$ (SigmaAldrich, CAS: 10294-41-4) as precursors. After that, the powder was dried at $120^{\circ} \mathrm{C}$ for $24 \mathrm{~h}$ and calcined at the temperature of $550^{\circ} \mathrm{C}$. The resulting catalysts were labeled as $x$ NiyCe/SBA-15, where $x$ and $y$ represent the wt. \% of nickel ( $\mathrm{x}=5$ or 10$)$ and cerium ( $\mathrm{y}=0,9$ or 18$)$.

$\mathbf{N}_{2}$ physisorption. Nitrogen adsorption/desorption isotherms were obtained on a TriStar II (Micromeritics) instrument at the temperature of 77 K. Catalysts were dried under vacuum at $170{ }^{\circ} \mathrm{C}$ for $12 \mathrm{~h}$ prior to the measurements. Specific surface area and pore size distribution were estimated in the relative pressure range of 0.05-0.25 according to the BET and BJH methods, ${ }^{[74,75]}$ respectively. Total pore volume was obtained from a single point measurement at $P / P_{0}=0.965$.

ICP. Inductively coupled plasma analysis for $\mathrm{Ni}$ and $\mathrm{Ce}$ was carried out using a 5100 ICP-OES instrument and SPS 4 Autosampler (Agilent), using argon as gas supply. Prior digestion of the samples, vessel was cleaned in nitric acid $(5 \mathrm{~mL})$. Two different digestion protocols were used: (1) a solution containing aqua regia and $\mathrm{HF}$ for nickel analysis, and (2) a solution of concentrated $\mathrm{HCl}$ for cerium analysis; at max 30 bar and $240^{\circ} \mathrm{C}$ bar in an UltraWAVE equipment (Milestone), in both cases. A calibration curve (4 plots) was built (1-10-25-100 ppm) and all samples have been duplicated.

PXRD. Powder $x$-ray diffractograms has been measured in a PANalytical X-Pert PRO instrument using a $\mathrm{Cu}$ Ka source $(\lambda=1.5418 \AA)$ in a Bragg-Brentano geometry, equipped with an X'Celerator and a RTMS $\mathrm{X}$ ray detector (active range of $2 \theta=2.18^{\circ}$ ). Data were acquired in the $2 \theta$ range of $10-80^{\circ}$, a step of $0.05^{\circ}$, and $250 \mathrm{~s}$ of acquisition time. The analysis of diffractograms was carried out using the X'Pert HighScore Plus v4.0 software (PANalytical).

TPR. Temperature programmed reduction profiles were measured using a TCD detector and commercial CuO (Sigma-Aldrich) for intensity calibration. A sample amount selected for consumption of ca. $100 \mu \mathrm{mol}-\mathrm{H}_{2}$ was pretreated in argon at $110^{\circ} \mathrm{C}$, cooled down up to $35^{\circ} \mathrm{C}$ and submitted to 
a reduction treatment in $50 \mathrm{~mL} \cdot \mathrm{min}^{-1}$ of $5 \% \mathrm{H}_{2} / \mathrm{Ar}$ (calibration mix) until $800^{\circ} \mathrm{C}$ using a heating ramp of $10^{\circ} \mathrm{C} \mathrm{min}-1$. All experimental parameters were carefully adjusted to prevent peak coalescence. ${ }^{[76]}$

$\mathrm{CO}_{2}$-TPD. Temperature programmed desorption of carbon dioxide experiments were conducted in an AMI-200 Altamira equipment. Before the experiment, circa $80 \mathrm{mg}$ of pelletized sample $(150-250 \mu \mathrm{m})$ were placed in a $U$ shaped quartz reactor and pre-reduced in $5 \% \mathrm{H}_{2} / \mathrm{Ar}$ flow at $750{ }^{\circ} \mathrm{C}$. After cooling to $35{ }^{\circ} \mathrm{C}$, a mixture of $25 \% \mathrm{CO}_{2} / \mathrm{He}$ was passed through the reactor for 30 minutes. Then, the sample was flashed with 30 $\mathrm{mL} \cdot \mathrm{min}^{-1}$ of helium flow for 15 minutes to purge the non-adsorbed carbon dioxide and heated up to $750^{\circ} \mathrm{C}$ with a heating ramp of $10^{\circ} \mathrm{C} \cdot \mathrm{min}^{-1}$. The latest step was recorded using a thermal conductivity detector.

TEM. Imaging of catalysts was performed in a Philips CM200 transmission electron microscope operating at $200 \mathrm{kV}$ in bright-field mode. Powder samples were deposited over a coated copper grid with lacey carbon before to loading onto the instrument. Histograms of particles sizes included in ESI were done by sampling 180 particles.

XPS. X-ray photoelectron spectroscopy measurements were conducted on a VG-ESCALAB 210 equipment provided of an analysis chamber at ultra-high vacuum conditions $\left(10^{-11}\right.$ bar) and a SPECS-Phoibos 100 hemispheric analyzer. Pelletized samples were loaded to the instrument in a pre-chamber at $10^{-9}$ bar. The catalysts were excited using an Al Ka xray source $(1486.6 \mathrm{eV})$ at $12 \mathrm{kV}$ and $20 \mathrm{~mA}$. Si $2 \mathrm{p}$ maximum intensity was set at $103.4 \mathrm{eV}$ for energy calibration, characteristic of silica. High resolution $\mathrm{Ni} 2 \mathrm{p}, \mathrm{Ce} 3 \mathrm{~d}, \mathrm{O} 1 \mathrm{~s}, \mathrm{Si} 2 \mathrm{p}$ and $\mathrm{C} 1 \mathrm{~s}$ spectra were recorded at 50 and $0.1 \mathrm{eV}$ of pass energy and a resolution, respectively. In situ treatments $\left(5 \% \mathrm{H}_{2} / \mathrm{Ar}\right.$ and $\mathrm{CO}_{2}: \mathrm{CH}_{4}$ at $\left.750{ }^{\circ} \mathrm{C}\right)$ were carried in a reaction chamber connected to the pre-chamber at atmospheric pressure. The spectra were treated and analyzed using CasaXPS v.2.3.17 software.

XAS. X-ray absorption spectroscopy in the EXAFS and XANES regions was recorded at the BM25A beamline of the European Synchrotron Radiation Facility (ESRF), located in Grenoble, France. An optimized amount of catalyst was pelletized and analyzed in transmission mode using a cell for in situ gas-solid reactions. XAS spectra were collected at room temperature, 500 and $750{ }^{\circ} \mathrm{C}$ in presence of $5 \% \mathrm{H}_{2} / \mathrm{Ar}$ flow $(50$ $\mathrm{mL} \cdot \mathrm{min}^{-1}$ ) from 8200 to $9100 \mathrm{eV}$ using a step of $0.5 \mathrm{eV}$. A standard nickelfoil measurement was used for energy calibration. The EXAFS patterns were Fourier transformed in the $1.9-12.5 \AA^{-1}$ range. The treatment and analysis of spectra was carried out using the IFEFFIT software.

Catalytic tests. Reaction tests were conducted in a 4-channel Flowrence XD platform from Avantium. Typically, $10 \mathrm{mg}$ of the catalyst was loaded in a quartz reactor. The catalysts were pelletized to obtain grains sized from 150 to $250 \mu \mathrm{m}$ before loading. The reactors are $300 \mathrm{~mm}$ long quartz tubes inserted in a furnace. The outside and inside diameters of the tubes are 3 and $2 \mathrm{~mm}$, respectively. One reactor was always used without catalyst as a blank. The mixed feed consisted of $1 / 1 / 1$ ratio of $\mathrm{CH}_{4} / \mathrm{CO}_{2} / \mathrm{N}_{2}$ mixture. We aimed for a WHSV of $60000 \mathrm{~mL} \cdot \mathrm{min}^{-1} \cdot \mathrm{gcat}^{-1}$. Prior to feeding the reaction mixture all samples were pretreated in situ with a pure $\mathrm{H}_{2}$ atmosphere for 1 hours at $750^{\circ} \mathrm{C}$. Gas product analysis was performed by an Agilent 7890B GC equipped with a TCD detector $\left(\mathrm{H}_{2}, \mathrm{He}, \mathrm{CO}\right)$ and two FID detectors for separate analysis of light hydrocarbons (C1-C9) and oxygenates $\left(\mathrm{CO}_{2}\right.$, alcohols). Helium was used as carrier gas for the FID channels. Argon was used as carrier in the TCD channel to enable detection of helium as internal standard and hydrogen as analyte. Conversions $(\mathrm{X}, \%)$ and carbon balance are defined as follows:

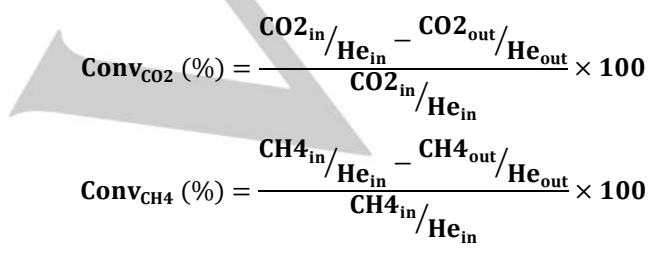

$$
\mathrm{C}_{\text {Balance }}(\%)=\frac{\sum \mathbf{C}_{\text {out }} / \mathbf{H e}_{\text {out }}}{\sum \mathbf{C}_{\text {in }} / \mathbf{H e}_{\text {in }}} \times 100
$$

where $\mathrm{Cin}$ and $\mathrm{Ci}_{\text {out, }}$, are the concentrations determined by GC analysis in the blank and in the reactor outlet respectively.

\section{Acknowledgements}

Funding for this work was provided by "Ministerio de Economia y Competitividad" of Spain (Project Nos. ENE2011-24412 and CTQ2014-60524-R) and King Abdullah University of Science and Technology (KAUST). Alberto Rodriguez-Gomez thanks the Spanish Government for the PhD fellowship (No. BES-2012061744). We acknowledge ESRF (BM25 SPLINE beamline) for their support. We also thank Sandra Ramirez Cherbuy for artwork.

\section{Keywords: Dry reforming $\cdot$ Ceria $\bullet$ Coke resistance $\bullet$ in situ XAS} - Nickel

[1] E.J. Schelter, Nature Chem. 2013, 5, 348-348.

[2] R.J. Gorte, AlChE J. 2010, 56, 1126-1135.

[3] T. Montini, M. Melchionna, M. Monai, P. Fornasiero, Chem. Rev. 2016 116, 5987-6041.

[4] J. Paier, C. Penschke, J. Sauer, Chem. Rev. 2013, 113, 3949-3985.

[5] J. Papavasiliou, M. Rawski, J. Vakros, G. Avgouropoulos, Chem CatChem 2018, 10, 2096-2106.

[6] F.B. Noronha, E.C. Fendley, R.R. Soares, W.E. Alvarez, D.E. Resasco, Chem. Eng. J. 2001, 82, 21-31.

[7] R. B. Duarte, M. Olea, E. Iro, T. Sasaki, K. Itako, J. A. van Bokhoven, ChemCatChem 2014, 6, 2898-2903.

[8] V.M. Gonzalez-DelaCruz, J.P. Holgado, R. Pereniguez, A. Caballero, J. Catal. 2008, 257, 307-314.

[9] A. Bruix, J.A. Rodriguez, P.J. Ramírez, S.D. Senanayake, J. Evans, J.B. Park, D. Stacchiola, P. Liu, J. Hrbek, F. Illas, J. Am. Chem. Soc. 2012 134, 8968-8974.

[10] A. Caballero, J.P. Holgado, V.M. Gonzalez-delaCruz, S.E. Habas, T. Herranz, M. Salmeron, Chem. Commun. 2010, 46, 1097-1099.

[11] X. Du, D. Zhang, L. Shi, R. Gao, J. Zhang, J. Phys. Chem. C 2012, 116, 10009-10016.

[12] S.M. Stagg-Williams, F.B. Noronha, G. Fendley, D.E. Resasco, J. Catal. 2000, 194, 240-249.

[13] S. Damyanova, J.M.C. Bueno, Appl. Catal. A-Gen. 2003, 253, 135-150.

[14] M. M. Rahman, T. L. Church, A. I. Minett, A. T. Harris, ChemSusChem 2013, 6, 1006-1013.

[15] R.B. Duarte, O.V. Safonova, F. Krumeich, M. Makosch, J.A. van Bokhoven, ACS Catal. 2013, 3, 1956-1964.

[16] N. Wang, K. Shen, L. Huang, X. Yu, W. Qian, W. Chu, ACS Catal. 2013, 3, 1638-1651.

[17] L. Li, D.H. Anjum, H. Zhu, Y. Saih, P.V. Laveille, L. D'Souza, J.M. Basset, ChemCatChem 2015, 7,427-433.

[18] Z. Cheng, Q. Wu, J. Li, Q. Zhu, Catal. Today 1996, 30, 147-155

[19] S.S.Y. Lin, D.H. Kim, S.Y. Ha, Appl. Catal. A-Gen. 2009, 355, 69-77.

[20] S.Y. Foo, C.K. Cheng, T.-H. Nguyen, A.A. Adesina, Catal. Today 2011, 164, 221-226.

[21] A. Carrero, A.J. Vizcaino, J.A. Calles, L. Garcia-Moreno, J. Energy Chem. 2017, 26, 42-48.

[22] P. Dutta, S. Pal, M.S. Seehra, Y. Shi, E.M. Eyring, R.D. Ernst, Chem. Mater. 2006, 18, 5144-5146.

[23] Z. Qiao, Z. Wu, S. Dai, ChemSusChem 2013, 6, 1821-1833.

[24] V.K. Paidi, L. Savereide, D.J. Childers, J.M. Notestein, C.A. Roberts, J. van Lierop, ACS Appl. Mater. Inter. 2017, 9, 30670-30678.

[25] A. Trovarelli, J. Llorca, ACS Catal. 2017, 7, 4716-4735.

[26] S. Zhang, S. Muratsugu, N. Ishiguro, M. Tada, ACS Catal. 2013, 3 1855-1864.

[27] N. Wang, W. Chu, T. Zhang, X.S. Zhao, Int. J. Hydrogen Energ. 2012, 37, $19-30$.

[28] N. Wang, Z. Xu, J. Deng, K. Shen, X. Yu, W. Qian, W. Chu, F. Wei, ChemCatChem 2014, 6, 1470-1480

[29] C.E. Daza, J. Gallego, F. Mondragón, S. Moreno, R. Molina, Fue/ 2010 89, 592-603.

[30] I. Luisetto, S. Tuti, C. Battocchio, S. Lo Mastro, A. Sodo, Appl. Catal. AGen. 2015, 500, 12-22.

[31] V.M. Gonzalez-Delacruz, F. Ternero, R. Pereñíguez, A. Caballero, J.P. Holgado, Appl. Catal. A-Gen. 2010, 384, 1-9.

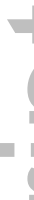


[32] A. Rodriguez-Gomez, R. Pereniguez, A. Caballero, Catal. Today 2018 , $307,224-230$.

[33] A. Rodriguez-Gomez, F. Platero, A. Caballero, G. Colon, Mol. Catal 2018, 445, 142-151

[34] X. Ning, Y. Lu, H. Fu, H. Wan, Z. Xu, S. Zheng, ACS Appl. Mater. Inter 2017, 9, 19335-19344.

[35] A. Rodriguez-Gomez, R. Pereniguez, A. Caballero, J. Phys. Chem. B 2018, 122, 500-510

[36] M. Akri, S. Zhao, X.Y. Li, K.T. Zang, A.F. Lee, M.A. Isaacs, W. Xi, Y. Gangarajula, J. Luo, Y.J. Ren, Y.T. Cui, L. Li, Y. Su, X.L. Pan, W. Wen, Y. Pan, K. Wilson, L. Li, B.T. Qiao, H. Ishii, Y.F. Liao, A.Q. Wang, X.D. Wang, T. Zhang, Nat. Commun. 2019, 10, 5181.

[37] E.G.M. Kuijpers, A.K. Breedijk, W.J.J. van der Wal, J.W. Geus, J. Catal. $1983,81,429-439$.

[38] X. Cai, Y.H. Hu, Energy Sci. Eng. 2019, 7, 4-29.

[39] Y. H. Hu, E. Ruckenstein, in Advances in Catalysis (Eds.: B. C. Gates, H. Knozinger), Elsevier Academic Press Inc, San Diego, 2004, pp 297 345.

[40] Y. H. Hu, E. Ruckenstein, Appl. Catal. A-Gen. 1995, 133, 149-161.

[41] Y. H. Hu, E. Ruckenstein, Catal. Rev. Sci. Eng. 2020, 44, 423-453.

[42] R. Pereñiguez, V. M. Gonzalez-delaCruz, A. Caballero, J. P. Holgado, Appl. Catal. B-Environ. 2012, 123-124, 324-332.

[43] R. Pereñiguez, V. M. Gonzalez-delaCruz, J. P. Holgado, A. Caballero, Appl. Catal. B-Environ. 2010, 93, 346-353.

[44] S. Das, J. Ashok, Z. Bian, N. Dewangan, M.H. Wai, Y. Du, A. Borgna, K. Hidajat, S. Kawi. Appl. Catal. B-Environ. 2018, 230, 220-236.

[45] Ş. Özkara-Aydınoğlu, E. Özensoy, A.E. Aksoylu, Int. J. Hydrogen Energ. 2009, 34, 9711-9722.

[46] Z. Alipour, M. Rezaei, F. Meshkani, J. Ind. Eng. Chem. 2014, 20, 28582863.

[47] K.S.W. Sing, D.H. Everett, R.A.W. Haul, L. Moscou, R.A. Pierotti, J. Rouquerol, T. Siemieniewska, Pure Appl. Chem. 1985, 57, 603-619.

[48] A. Rodriguez-Gomez, A. Caballero, ChemNanoMat 2017, 3, 94-97.

[49] J.-Y. Luo, M. Meng, J.-S. Yao, X.-G. Li, Y.-Q. Zha, X. Wang, T.-Y. Zhang, Appl. Catal. B-Environ. 2009, 87, 92-103.

[50] E. Gaigneaux, M. Devillers, S. Hermans, P.A. Jacobs, J. Martens, P. Ruiz in Scientific Bases for the Preparation of Heterogeneous Catalysts: Proceedings of the 10th International Symposium, July 11-15, Elsevier, Louvain-la-Neuve, Belgium, 2010.

[51] C. Xu, Y. Wu, S. Li, J. Zhou, J. Chen, M. Jiang, H. Zhao, G. Qin, J. Mater. Sci. Technol. 2020, 40, 39-46.

[52] M. A. A. Aziz, A. A. Jalii, S. Wongsakulphasatch, D. N. Vo, Catal. Sci. Technol. 2020, 10, 35-45.

[53] P. Burroughs, A. Hamnett, A.F. Orchard, G. Thornton, J. Chem. Soc., Dalton Trans. 1976, 1686-1698.

[54] E. Bêche, P. Charvin, D. Perarnau, S. Abanades, G. Flamant, Surf. Interface Anal. 2008, 40, 264-267.

[55] S. Deshpande, S. Patil, S. Kuchibhatla, S. Seal, Appl. Phys. Lett. 2005 87, 133113(1-3).

[56] D.R. Mullins, S.H. Overbury, D.R. Huntley, Surf. Sci. 1998, 409, 307319.

[57] F. Zhang, P. Wang, J. Koberstein, S. Khalid, S.-W. Chan, Surf. Sci. 2004, 563, 74-82.

[58] M. V. Ganduglia-Pirovano in Defects at Oxide Surfaces (Eds.: J. Jupille, G. Thornton), Springer International Publishing, Cham, 2015, pp 149190.

[59] V. Calvino-Casilda, A.J. López-Peinado, R.M. Martín-Aranda, E.P. Mayoral in Nanocatalysis: Applications and Technologies, CRC Press, 2019.

[60] K.O. Hodgson, B. Hedman, J.E. Penner-Hahn in EXAFS and Near Edge Structure III: Proceedings of an International Conference, July 16-20, Springer Berlin Heidelberg, Stanford, CA, 1984.

[61] A. Anspoks, A. Kalinko, R. Kalendarev, A. Kuzmin, Phys. Rev. B 2012, 86, 174114(1-11)

[62] J. de Graaf, A.J. van Dillen, K.P. de Jong, D.C. Koningsberger, J. Catal. 2001, 203, 307-321.

[63] A. Jentys, Phys. Chem. Chem. Phys. 1999, 1, 4059-4063.

[64] J. Matos, L.K. Ono, F. Behafarid, J.R. Croy, S. Mostafa, A.T. DeLaRiva, A.K. Datye, A.I. Frenkel, B. Roldan Cuenya, Phys. Chem. Chem. Phys. 2012, 14, 11457-11467.

[65] D. Pakhare, J. Spivey, Chem. Soc. Rev. 2014, 43, 7813-7837.

[66] J. Zhang, H. Wang, A.K. Dalai, J. Catal. 2007, 249, 300-310.

[67] J.-H. Kim, D.J. Suh, T.-J. Park, K.-L. Kim, Appl. Catal. A-Gen. 2000, 197, 191-200.

[68] S. Tang, L. Ji, J. Lin, H.C. Zeng, K.L. Tan, K. Li, J. Catal. 2000, 194, $424-430$

[69] Y. Song, E. Ozdemir, S. Ramesh, A. Adishev, S. Subramanian, A. Harale, M. Albuali, B.A. Fadhel, A. Jamal, D. Moon, S.H. Choi, C.T. Yavuz, Science 2020, 367, 777-+.

[70] C. Montero, A. Ochoa, P. Castano, J. Bilbao, A.G. Gayubo, J. Catal. 2015, 331, 181-192.

[71] Z. Wang, X.M. Cao, J. Zhu, P. Hu, J. Catal. 2014, 311, 469-480.

[72] J.C. Guevara, J.A. Wang, L.F. Chen, M.A. Valenzuela, P. Salas, A. García-Ruiz, J.A. Toledo, M.A. Cortes-Jácome, C. Angeles-Chavez, O. Novaro, Int. J. Hydrogen Energ. 2010, 35, 3509-3521.
[73] D. Zhao, J. Feng, Q. Huo, N. Melosh, G.H. Fredrickson, B.F. Chmelka, G.D. Stucky, Science 1998, 279, 548-552.

[74] E.P. Barrett, L.G. Joyner, P.P. Halenda, J. Am. Chem. Soc. 1951, 73, 373-380.

[75] S. Brunauer, P.H. Emmett, E. Teller, J. Am. Chem. Soc. 1938, 60, 309319.

[76] P. Malet, A. Caballero, J. Chem. Soc., Faraday Trans. 1 1988, 84, 23692375. 


\section{WILEY-VCH}

\section{FULL PAPER}

\section{Entry for the Table of Contents}

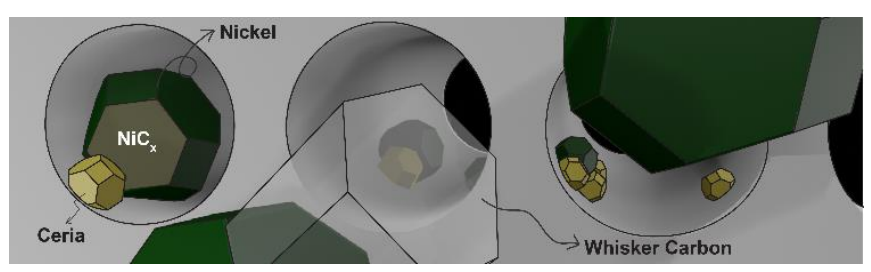

Coke formation has been the main drawback for the industrial implementation of the dry reforming of methane to syngas. Highly dispersed nickel nanoparticles promoted by ceria has shown to be a very promising catalyst for that purpose. Ceria has proven to enhance $\mathrm{CO}_{2}$ activation and coke removal as well as the nickel dispersion over the support, thus decreasing the rate for coke formation. 